\title{
Laparoscopic nephrectomy for the treatment of renal tumors at Thanh Hoa General Hospital in Vietnam
}

\author{
T. T. Tung ${ }^{1}$, T.B. Giang ${ }^{2}$, L.Q. Anh ${ }^{1}$ and N.A. Luong ${ }^{1}$ \\ ${ }^{1}$ Department of Urology of Thanh Hoa General Hospital, Vietnam \\ ${ }^{2}$ Department of Emergency abdominal surgery of Viet Duc University \\ Hospital, Vietnam \\ Corresponding author: T.B. Giang \\ E-mail: tbgiangvd@gmail.com
}

Genet. Mol. Res. 20 (1): gmr18748

Received December 30, 2019

Accepted April 20, 2020

Final Revision January 25, 2021

Published March 30, 2021

DOI http://dx.doi.org/10.4238/gmr18748

\begin{abstract}
We evaluated the results of laparoscopic nephrectomy for the treatment of renal tumors in a provincial hospital. Subjects and methods: 30 patients were diagnosed with renal tumors and underwent laparoscopic nephrectomy at a General Hospital, in Vietnam. The mean age was 53.23 years, the rate of incidental detection of tumors was $8 / 30$. Average tumor size was $5.33 \mathrm{~cm}$. Angiomyolipoma was found int $7 / 30$ and renal cell carcinoma (RCC) in 23/30. The transperitoneal approach was used in 13/30. Most (21/30) patients had one renal artery and one renal vein. The mean operative time was 116 minutes, the average blood loss $161 \mathrm{ml}$, the drainage time five days and the hospital stay six days. Operative complications: minor hemorrhage 2/30; major haemorrhage $1 / 30$. Postoperative complications: $3 / 30$. Conversion to open surgery $1 / 30$. Most (18/30) patients were examined after six months; one case had liver metastases. Laparoscopic nephrectomy (LRN) in the treatment of renal tumors is a safe, effective method and can be done in provincial hospitals. However, in order to make a more accurate conclusion, there is a need for large-scale studies with a longer follow-up time.
\end{abstract}


Key words: Renal function; laparoscopic surgery; Renal tumor; Radical nephrectomy; Partial nephrectomy

\section{INTRODUCTION}

Kidney cancer accounts for $85-90 \%$ of kidney tumors and about $2 \%-3 \%$ of adult cancers. Thanks to the development of modern imaging devices such as ultrasound, CT, and MRI, the rate of accidental detection of early-stage kidney tumors is on the rise, which is in Vietnam. From 14 - 25\%, and in the U.S.A. from 48 - 66\% (Gill et al., 2010; Krabbe et al., 2014; Vũ Nguyễn Khải Ca Và , 2015; Janicic et al., 2016).

Early, localized kidney tumors are often chosen to be treated with partial or radical nephrectomy. Laparoscopic radical nephrectomy (LRN) was first performed in 1992. It is a minimally invasive procedure and has the same therapeutic efficacy as open radical nephrectomy (ORN). Radical endoscopic nephrectomy is currently being performed more and more; it is estimated that over the past 10 years there have been more than 10,000 cases of radical endoscopic nephrectomy worldwide, which has significantly increased survival after surgery for about $65 \%$ of local kidney cancer cases (Ono et al., 2005; Vũ Lê Chuyên, 2007; Krabbe et al., 2014; Liu et al., 2017). Data from several studies claim that LrRN showed less analgesia requirement, shorter convalescence time, and less blood loss intraoperatively, while operative time and postoperative complication were the same.

Laparoscopic surgical approaches to the kidney presently include transperitoneal, retroperitoneal, hand-assisted, robotic, laparoendoscopic single-site surgery (LESS), and natural orifice transluminal endoscopic surgery (NOTES). With each approach, a pneumoperitoneum is created to increase the intra- abdominal working space (Yang et al. 2019). In Vietnam, kidney laparoscopic surgery was applied from 2002 to 2003 at Viet Duc Hospital, Ho Chi Minh City Medical University Hospital, Binh Dan Hospital. This surgery has been applied in many health facilities at the central level. At provincial health facilities, this procedure is only available in a few places. Thanh Hoa General Hospital has been using this surgery since 2014 . We conducted this study to evaluate the results evaluate the advantages of laparoscopic surgery.

\section{MATERIAL AND METHODS}

\section{Subject of research}

The study included 30 patients diagnosed with kidney tumors and who underwent laparoscopic surgery at the Department of Urology, Thanh Hoa Provincial General Hospital. All the participants agreed to take part in this experiment and do not disclaim the results of the study to be shown in the research paper.

All manipulations were in according to the moral standards of the responsible committee on human experimentation (institutional and national) and with the Helsinki Declaration of 1975, as revised in 2000. Based on the selection designation for nephrectomy, benign neoplasm and malignant neoplasm diagnosed at pT1 and pT2 stages that has not spread to the regional lymph nodes and have not spread far, based on the anatomical results after surgery. All cases had a normal opposite kidney. We excluded 
tumors that could severely damage the kidney (tumor size $\leq 4 \mathrm{~cm}$, tumor on the periphery and protruding from the kidney surface).

\section{Research methods}

The research used descriptive and retrospective data. The patients were diagnosed and performed the surgery according to a unified procedure, with a Karl Storz Full HD laparoscope by the same surgical team, using a Hamonic scalpel Gen 11 ultrasound scalpel from Ethicon Endo-Surgery, and Hem-o-lock clips of size 5 and $10 \mathrm{~mm}$. Patient preparation: All patients underwent endotracheal anesthesia, gastric catheterization, urethral catheterization and intestinal cleansing prior to surgery. Surgical procedure: All patients underwent radical nephrectomy by abdominal or posterior peritoneal surgery. ** Periteal route: The patient was inclined to the opposite of 700 with lumbar padding. Place the first trocar according to the open method, the rest of the trocar is placed under the observation of the scope, the position of the trocar as shown in Figure 1a. Pump $\mathrm{CO}_{2}$ gas with pressure $\leq$ $12 \mathrm{mmHg}$, initial pump speed $2-31 / \mathrm{min}$.

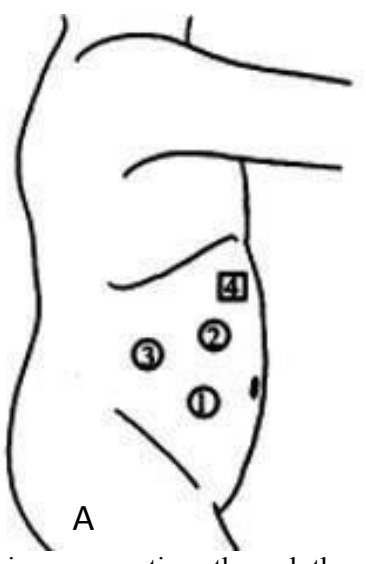

Figure 1. Endoscopic access options through the retroperitoneal abdomen

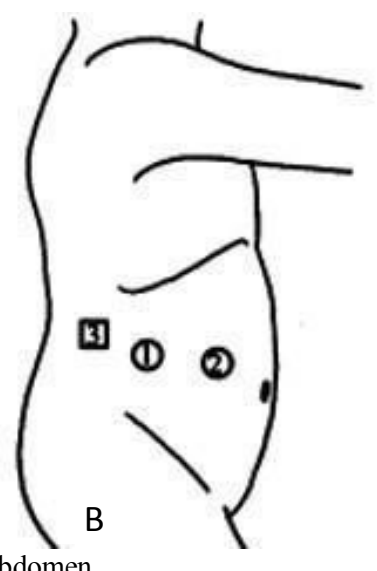

For the right side kidney surgery: surgery to lower the angle of the liver and the colon, revealing the front of the right kidney, surgery to continue to the kidney, find arteries and kidney veins to control and clip cut with clip or Hem-o-lock. Liberation around the kidneys. Clamp and cut the ureter in the upper $1 / 3$ section with Hem-o-lock. Collect the whole sample with a plastic bag through the incision in the same pelvic area. Check sectional hemostasis and additional hemostasis. Renal drainage of kidney holes, closing the trocar layer 2 layers.

For left side kidney surgery: similar, but right down the angle of the spleen and lower colon.

Retroperitoneal line: The patient is inclined to the opposite of 900 with padded waist area Place the first trocar according to the open method, the rest of the trocar is placed under the observation of the looking glass, the position of the trocar is shown in Figure 1b. Pump $\mathrm{CO}_{2}$ gas with pressure $\leq 12 \mathrm{mmHg}$, initial pump speed $2-31 / \mathrm{min}$. 
For the right kidney surgery: surgery on the kidney stem, revealing the artery and veins of the kidneys to control and clamp with clip or Hem-o-lock. Liberation around the kidneys. Clamp and cut the ureter in the upper 1/3 section with Hem-o- lock. Collect the whole sample with a plastic bag through the same pelvic skin incision. Check sectional hemostasis and additional hemostasis. Renal drainage of kidney holes, closing the trocar two layers.

For surgery on the left: similar.

Care and indicators to consider:

Patients were monitored for pulse, arterial blood pressure, breathing, temperature and drainage postoperative status. Antibiotics use the $\beta$ lactamine group in combination with the quinolon group. Reduce non-steroidal and morphine pain. The indicators are recorded: time of surgery, control and clamping technique for vascular cutting, amount of blood loss, number of trocars, time for draining the drain, length of hospital stay, complications - complications. Check back after 3 and 6 months (clinical, ultrasound, and laboratory data).

\section{RESULTS}

The characteristics of study's 30 participants are summarized in Table 1.

These are the factors that affected operating time and surgery outcomes the most. There were 16 male and 14 female patients, although sex does not play a key role.

Blood loss depends on some factors, such as tumor size and complexity.

These factors also affect operative time.

Patients mainly had typical complaints, which are presented in the table. The prognosis of renal tumor mainly depends on histology. As abdominal imaging is getting more and more popular the amount of small renal has increased in recent decades.

\section{Table 1. Characteristics of the kidney surgery patients.}

\begin{tabular}{|c|c|}
\hline Variable & Mean (range) or amount of patient or ratio (\%) \\
\hline Age (years) & $53.23(28-80)$ \\
\hline Sex (male/female) & $16 / 14$ \\
\hline Located side (right/left) & $17 / 13$ \\
\hline Size of tumor $(\mathrm{cm})$ & $5.33(4-7)$ \\
\hline \multicolumn{2}{|l|}{ Location of tumor } \\
\hline Upper polar & 9 \\
\hline Middle part & 14 \\
\hline Lower polar & 7 \\
\hline \multicolumn{2}{|l|}{ Present symtoms* } \\
\hline Have symtoms & 22 \\
\hline Incidental diagnosis & 8 \\
\hline \multicolumn{2}{|l|}{ Staging $* *$} \\
\hline pT1a & 5 \\
\hline $\mathrm{pT} 1 \mathrm{~b}$ & 15 \\
\hline pT2 & 3 \\
\hline$\geq \mathrm{pT} 3$ & 0 \\
\hline \multicolumn{2}{|l|}{ Histology } \\
\hline \multicolumn{2}{|l|}{ Benign } \\
\hline Angiolypomioma & 7 \\
\hline \multicolumn{2}{|l|}{ Renal cell carcinoma } \\
\hline Clear cell & 18 \\
\hline Papillary & 3 \\
\hline Chromophobe & 2 \\
\hline
\end{tabular}


Table 2. Surgical characteristics and results of the kidney tumor operations.

\begin{tabular}{ll}
\hline Variable & Mean (range) or amount of patient or ratio (\%) \\
\hline Approach & 13 \\
Transperitoneal & 17 \\
Retroperitoneal & \\
Amount of trocars & 13 \\
3 & 14 \\
4 & 3 \\
5 & $116.17(80-255)$ \\
Operative time (minutes) & \\
Blood vessel of renal hilar & 21 \\
1 artery and 1 vein & 9 \\
More than: 1 artery or 1 vein & 1 \\
Renal vascular control & 29 \\
Hilar ligating en block $* *$ & 161.67 \\
Vessels ligated separate & $5(4-6)$ \\
Blood loss (ml) & $6(5-7)$ \\
Remove drainage time (days) & 2 \\
Hospital stay (days) & 1 \\
Operative complications & 1 \\
Dissected interface bleeding & \\
Blood vessel of renal hilar & 3 \\
bleeding $* *$ & \\
Postoperative complications & \\
Neuromuscular pain & 21 \\
Examine postoperatively **** & 18 \\
03 months &
\end{tabular}

Whether it is a left or right renal operation, the key and first step are to search for and deal with the renal artery. After finding the renal artery and clamping it with Hem-olok, the safety of the operation is largely guaranteed, and the surgeon will become much calmer when he or she handles the renal vein.

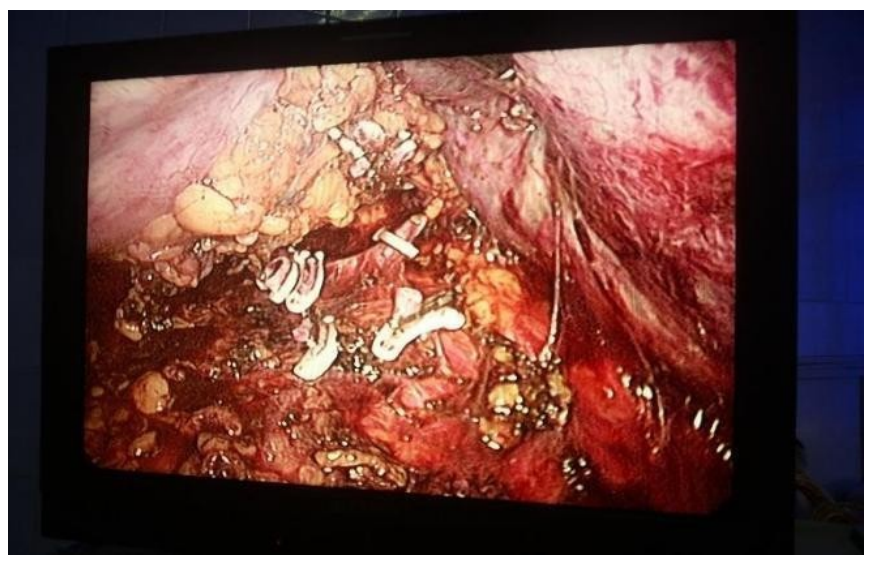

Figure 2. Blood vessels of kidney are clamped by Hem-o-lock and titanium clips. 


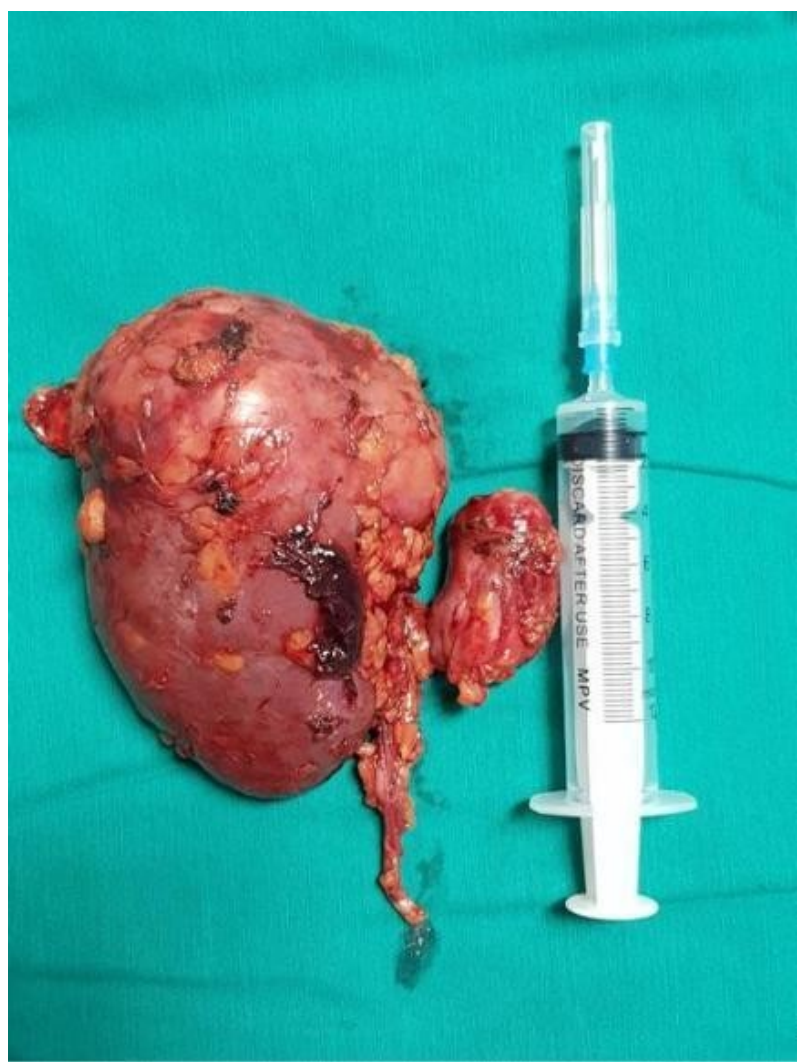

Figure 3. Specimens after removal (kidney and lymph nodes).

\section{Characteristics of patients}

Patients in our study had an average age of 53.23 years, male $/$ female ratio $=16 / 14$, right kidney tumor had 17 cases, the rate of tumor was found by chance (no manifestations) was $8 / 30$. The main symptoms were dull ache in the lower back, hematuria, fever, and weight loss. Kidney tumors are more common in middle-aged adults and up to twice as many men as women, right on the right side is similar to the left, tumors on the two sides are common in von Hippel's disease - Lindau (Nguyễn Bửu Triều, 2003). Vu Nguyen Khai Ca Và (2015) and Truong Thanh Tung (2005), who studied kidney cancer at Viet Duc Hospital and Central Military Hospital 108, showed that the rate of accidental detection of kidney tumors was about $14-25 \%$.

\section{Surgical indications}

Indications for surgical treatment of kidney tumors are generally based on tumor characteristics and stage, following the 2014 Canadian Cancer Society guidelines for the treatment of cell carcinoma. Kidneys: for tumors that are still in the pT1 stage to return often indicate partial kidney resection; For pT2 and pT3a tumors, radical nephrectomy is preferred. Partial nephrectomy or radical nephrectomy can be performed by laparoscopic 
surgery, but most authors agree that partial renal endoscopy is often indicated for kidney tumors. In pT1a and below, the tumor is not too deep into the renal parenchyma, has sufficient distance to the renal pelvis and not near the large blood vessels of the kidney; Radical nephrectomy is usually indicated for kidney tumors from $\mathrm{pT} 1 \mathrm{~b}$ to $\mathrm{pT} 3 \mathrm{a}$, but for kidney tumors $\mathrm{pT} 3 \mathrm{~b}$ or more, it is very rare to undergo kidney endoscopy due to kidney tumors at this time. Have been invaded the surrounding organ or invaded a vein or vein (Ono et al., 2005; Rendon et al., 2014; van Oostenbrugge et al. 2018).

The patients in our study had tumors at pT2 stage and below, the average tumor size was $5.33 \mathrm{~cm}$, of which p $1 \mathrm{~b}$ tumors accounted for $15 / 30=50 \%$. There are 7 cases of benign neoplasm and 5 cases of nephropathy in pTla stage but not indicated for partial renal resection because the tumor is located in the middle part of the kidney, deep into the parenchyma and close to the pyramidal system. Access road and number of trocars:

For radical laparoscopic surgery, it is feasible to follow the peritoneal or retroperitoneal route. The abdominal cavity is usually wide, with clear anatomical landmarks, but the access to the renal vein is not as direct as the retroperitoneal line. Ono Y. said that the retroperitoneal route has a smaller workspace, but the operation time is shorter than the peritoneal route, especially in the case of old peritoneal surgery, the retroperitoneal route will be the option to choose the optimal. The peritoneal passage is suitable for cases where an indication for complete removal of the kidneys, ureters and a part of the bladder wall due to tumor excretion, because after the ablation of the kidneys and upper ureters is complete, the surgeon only turning down and cutting the lower ureter and the wall of the bladder without having to create cavity like retroperitoneal line (Ono et al. 2005; Rendon et al. 2014; Fariborz et al. 2017).

In this study, the selection of the entrance is usually based on a number of criteria such as: having a history of surgery on the upper abdomen, choosing the retroperitoneal route; the size of the tumor is larger, the location of the tumor in the upper pole or in cases of excretion, then select the route through the abdominal cavity. Results showed that we had $13 / 30$ in the abdominal route and 17/30 in the retroperitoneal route. Through the cases we have studied, the retroperitoneal route often has more advantages than the abdominal route if the surgery is large enough to control the renal artery vessels. The number of trocars we use for all cases is from 3 to 5 . With the case of retroperitoneal route, three trocars are sufficient, while the route through the abdomen can use 1 more Organ trojans even add a working trocar.

\section{Treatment of renal vein blood vessels}

Angioplasty is a key step in radical laparoscopic surgery. The general principle is to undergo surgery and early control of renal vein vessels, control arteries before posterior veins. Surgery required in these areas is the use of a prison head device, the kidney stem must always be stretched to identify the kidney vessels and its appendages, when the surgery must remove all surrounding organizations. to release each circuit separately and then clip with a clip, Hem-o- lock or Endo-GIA (Gill et al., 2010; Krabbe et al., 2014; Yang et al. 2019). For foreign authors, the use of Endo-GIA for renal vein cutting or entire renal vein block is widely applied, but the cost to use Endo-GIA is relatively high. Vu Le Chuyen, through his research on laparoscopic surgery, found that the combination of clips, 
Hem-o-lock and fastening just to clamp the kidneys is safe and suitable for Vietnamese conditions. However, he still warned against relying solely on Hem-o-lock alone.

Preliminary examination of patients showed $70 \%$ with one artery and one vein , and $30 \%$ with more than one artery or more than one vein. The case of retroperitoneal access often straight into the kidney, favorable for vascular processing. Cases of entry through the abdominal cavity must be operated on the upper edge of the kidney to find and treat the renal vessels, sometimes to the lower edge of the kidney, in combination with the stretching of the renal pelvis and upper ureter to find and treat kidney vessels. We perform forceps cutting of kidney arteries and veins with clips, Hem-o-lock, and ligation. For each circuit, we usually clip alternating with both clip and Hem-o-lock according to the principle of Hem-o- lock and the clip must cover the circumference of the circuit, in case the circumference is too big for the size of Hem -o-lock and clip, they must be tied again with a small aperture before clamping again with Hem-o-lock and clip. We have one case of bleeding during the treatment of renal vascular artery (breaking into the premature division of sub-artery) to transfer open surgery and clamp cut together the renal peduncle into a mass with vicryl and line only.

\section{Liberation around the kidney and ureter cut}

In the process of surgical release around the kidneys, we always get the maximum amount of fat around the kidneys and Gerota weight, there is no case to cut the adrenal gland together or dredge regional lymph nodes. Our ureters were cut at the level of $1 / 3$ above. There were four cases with old surgery, when the kidney stem and near the renal pelvis have the phenomenon of sticking to use an ultrasonic knife (Benway et al. 2009).

Traditionally, radical nephrectomy would include total nephrectomy, periportal fat layer, Gerota scales, lateral adrenal gland and regional lymph node dredging. However, at present, there are some viewpoints that change. Gabr et al. (2014) proposed cutting only adrenal glands along the side when there is suspicion of adrenal gland invasion on images taken before surgery or found during surgery. Ono et al. (2005) wrote that regional lymph node dredging is also not beneficial in terms of treatment efficacy compared to non-regional lymph node dredge.

\section{Complications}

The surgical results showed that the average operating time was 116 minutes; only four cases were old surgery with an average operating time of 216 minutes. The average blood loss was $161 \mathrm{ml}$, drainage time and hospitalization time were five and 6 days, respectively.

Accident during surgery: bleeding area accounted for $2 / 30$; hemorrhagic vascular bleeding $1 / 30$. Complications after surgery $10 \%$; all cases involved neuromuscular pain, which was resolved after a few days of treatment. One patient had open surgery; this was a case of bleeding during the treatment of renal vascular artery due to violation of a subbranch of premature division of the artery.

Through the study of the complications and complications of radical nephrectomy by laparoscopic surgery, the rate of common complications was 6/30, namely complications: bleeding; intestinal damage; fever; translation fluid; and neuromuscular pain. 
Thereby, he also warned that factors such as advanced age and heavy bleeding in surgery are potential risks that could increase the rate of postoperative complications (Zhang et al., 2013).

\section{Check after three and six months}

After six months, we checked 21 patients, accounting for $70 \%$. Patients had no hernias, trocar leg, local recurrence or distant metastasis.

After 6 months, we checked 18 patients, accounting for $60 \%$. There was one case of metastatic liver; this was a case of post-tumor tumor. This patient lived for nine months after the operation.

Nowadays, numerous studies found out that patients undergoing ORN had a decreased rate of surgical complications, length of stay, need for blood transfusion, etc. With recognition of this fact, this method is becoming more and more popular (Cwach and Kavoussi, 2016).

Laparoscopic renal surgery is far from being perfected. Physician's goals for the future are to improve outcomes, decrease length of recovery while trying to be cost effective and as least invasive as possible (Benway et al. 2009).

Robotic technologies are being developed, which can assist in completing different operations. It includes image guided robots that can help to introduce instrument or needles into the kidney safely to avoid organ injury.

Also in robot assisted partial nephrectomy (RAPN), tumor complexity does not affect operative time, while for LPN it does (Faiena et al. 2014; Bolton and Lynch, 2018; Luk et al. 2018).

\section{CONCLUSIONS}

Through researching 30 cases of autopsy surgery to treat kidney tumors at Thanh Hoa Provincial General Hospital, we found:

The average age of patients was 53.23 years, the ratio of male / female $=16 / 14$, the rate of tumors was discovered casually was $27 \%$. Average tumor size

Was $5.33 \mathrm{~cm}$. Vascular muscle tumors accounted for $23 \%$, renal cell carcinoma (RCC) $77 \%$.

Access to the abdominal cavity accounted for $43.33 \%$, the retroperitoneal access $56.67 \%$. A total of $70 \%$ of patients had eon artery and one vein; the rest had more than one artery or more than one vein. Treatment of renal peduncle clamp with Hem-o-lock, titanium clip and thread tie. The average surgical time was 116 minutes, the average blood loss was $161 \mathrm{ml}$, the withdrawal time was five days and the hospital stay was six days. Accident during surgery: bleeding area accounted for 2/30; hemorrhagic vascular bleeding 1/30. Complications after surgery: neuromuscular pain 3/30. Open surgery was needed in 1/30.

After three months of postoperative examination, 21/30 patients had no hernia, trocar leg, local recurrence or distant metastasis. Examination after six months of surgery was available for 18/30 patients; there was one case of metastatic liver; the extra life time after surgery was nine months. 


\title{
ACKNOWLEDGMENTS
}

The authors would like to thank the Department of Urology, Thanh Hoa Provincial General Hospital for the support during the research.

\section{CONFLICTS OF INTEREST}

\author{
The authors declare no conflict of interest.
}

\section{REFERENCES}

Benway BM, Bhayani SB, Rogers CG, Dulabon LM, et al. (2009). Robot assisted partial nephrectomy versus laparoscopic partial nephrectomy for renal tumors: a multi-institutional analysis of perioperative outcomes. $J$. Urol. 182(3): 866-873.

Bolton EM and Lynch TH (2018). Impact of warm ischaemia time during partial nephrectomy on renal function-is it really a matter of time? BJU Int. 121(1): 3-4.

Cwach K and Kavoussi L (2016). Past, present, and future of laparoscopic renal surgery. Investig. Clin. Urol. 57 (Suppl 2): $110-113$.

Faiena I, Han CS and Olweny EO (2014). Laparoscopic partial nephrectomy: state of the art review. Open Acc. Surg. 7: 59-69.

Fariborz B, Pusztai C, Farkas L, Buzogány I, et al. (2017). Laparoscopic partial nephrectomy in warm ischemia: imapct of parenchymal loss on kidney function. Magyar Urol. 2017(4): 158-166.

Gabr AH, Steinberg Z, Eggener SE and Stuart Wolf Jr J (2014). Indications for adrenalectomy during radical nephrectomy for renal cancer. Arab J. Urol. 12(4): 304-308.

Gill IS, Aron M, Gervais DA and Jewett MA (2010). Clinical practice. Small renal mass. N. Engl. J. Med. 362(7): 624634.

Janicic A, Bumbasirevic U, Pekomezovic T, Cekerevac M, et al. (2016). Partial versus radical nephrectomy for pT1a renal cancer in Serbia. J. BU ON. 21(6): 1449-1453.

Krabbe LM, Bagrodia A, Margulis V and Wood CG (2014). Surgical management of renal cell carcinoma. In Seminars in Interventional Radiology (Vol. 31, No. 1, p. 27). Thieme Medical Publishers.

Liu G, Ma Y, Wang S, Han X, et al. (2017). Laparoscopic versus open radical nephrectomy for renal cell carcinoma: a systematic review and meta-analysis. Transl. Oncol., 10(4):501-510.

Luk ACO, Pandian RMK and Heer R (2018). Laparoscopic renal surgery is here to stay. Arab J. Urol. 16(3): 314-320.

Nguyễn BT (2003). Bệnh Học Tiết Niệu. Hà Nội: NXB Y Học.

Ono Y, Hattori R, Gotoh M, Yoshino Y, et al. (2005). Laparoscopic radical nephrectomy for renal cell carcinoma: the standard of care already? Curr. Opin. Urol. 15(2): 75-78.

Rendon RA, Kapoor A, Breau R, Leveridge M, et al. (2014). Surgical management of renal cell carcinoma: Canadian Kidney Cancer Forum Consensus. Can. Urol. Assoc. J. 8(5-6): e398-e412.

Trương TT (2005). Đặc điểm lâm sàng, cận lâm sàng, mô bệnh học và chẩn đoán ung thu thận ở nguời lón. Luận văn thạc sĩ. Học Viện Quân Y.

van Oostenbrugge TJ, Fütterer JJ and Mulders PF (2018). Diagnostic imaging for solid renal tumors: a pictorial review. Kidn. Canc. 2(2): 79-93.

Vũ LC (2007). Áp dụng kỹ thuật cắt bỏ thận qua nội soi. Đề tài nghiên cứu cấp Thành Phố năm. Hồ Chí Minh: Sở Y Tế TP.

Vũ NKCV (2015). Nhận xét đặc điểm lâm sàng, cận lâm sàng và kết quả điều trị phẫu thuật ung thư thận tại bệnh viện Việt Đức từ năm 2012 đến 2014. Y Học TP HCM. 19(4): 264-269.

Yang F, Zhou Q, Li X and Xing N (2019). The methods and techniques of identifying renal pedicle vessels during retroperitoneal laparoscopic radical and partial nephrectomy. W. J. Surg. Oncol. 17(1): 1-8.

Zhang ZL, Li YH, Luo JH, Liu ZW, et al. (2013). Complications of radical nephrectomy for renal cell carcinoma: a retrospective study comparing transperitoneal and retroperitoneal approaches using a standardized reporting methodology in two Chinese centers. Chin. J. Cancer. 32(8): 461-468. 